\title{
Trace element geochemistry of carbonates in the Jurassic Lusitanian Basin records mineral- fluid interactions
}

\author{
Mário A. Gonçalves ${ }^{1,2, *}$, Maja Vuckovic $^{1}$, Alfonso Fiorelli ${ }^{1}$, Pedro Barrulas $^{3}$, and José \\ Mirão $^{3,4}$ \\ ${ }^{1}$ Department of Geology, Faculty of Sciences, University of Lisbon, Campo Grande, 1749-016 \\ Lisbon, Portugal \\ ${ }^{2}$ IDL - Instituto Dom Luíz, Faculty of Sciences University of Lisbon, Campo Grande, 1749-016 \\ Lisbon, Portugal \\ ${ }^{3}$ HERCULES Lab, University of Évora, 7000 Évora, Portugal \\ ${ }^{4}$ Geosciences Department, University of Évora, 7000 Évora, Portugal
}

\begin{abstract}
Carbonate rocks in sedimentary basins are reactive and can record complex histories of events associated with fluid flow in these basins. These include processes of dolomitization and dedolomitization. In this work we provide some preliminary data where distinct calcite and dolomite generations in the Jurassic Lusitanian Basin were analysed by LA-ICP-MS for trace elements in order to characterize chemical signatures of fluid-mineral interaction. It was observed that different carbonate generations can preserve the range of certain trace metal concentrations, but later calcites have distinctly higher contents in REE, Th and $\mathrm{U}$, and $\mathrm{Ba}$. Dolomites also show distinct chemical signatures but lack of analytical and spatial resolution does not allow quantification of the precursor calcite relicts. However, these processes point to the action of basinal fluids triggered by distinct tectonic episodes and associated volcanic activity.
\end{abstract}

\section{Introduction}

Carbonate sedimentary basins such as the Lusitanian Basin (LB) of Middle Jurassic age located in West-Central Portugal, show many textural features of polyphasic mineral formation including dolomitization. Dolomite occurrence in the LB seems to be either stratigraphically or tectonically controlled. Most sediments of the LB are of Jurassic age, but its sedimentary history include units deposited from Late Triassic to Late Cretaceous [1]. The base of the LB is marked by the occurrence of evaporitic rocks, some currently outcropping by means of tectonically-driven diapirism. The LB marks several rifting episodes related to the opening of the Atlantic Ocean before the occurrence of an episode of tectonic inversion which gave rise to its present architecture [2]. The intrusion of plutonic igneous rocks occurred in the LB until late-Cretaceous time. All these events caused reworking and recrystallization of carbonate rocks within the basin, including dolomites,

\footnotetext{
*Corresponding author: mgoncalves@ ciencias.ulisboa.pt
} 
and generated extensive fluid flow along fractures, faults, and sedimentary units. These episodes likely influenced the formation of dolomites and late-precipitated carbonates in the LB through interactions with diagenetic basinal fluids and subsequent fault-controlled fluid flow. This study examined carbonate mineralogy, textures, and chemical composition to provide a first approach for fluid characterization.

\section{Sampling and Methods}

Samples from limestones and dolomites were taken from three distinct locations (PE, CHA, and VAL) in the Southern part of the "Maciço Calcário Extremenho" (70 km N of Lisbon), including some carbonate precipitates from large-scale fault zones, which were observed in reflected and transmitted light microscope and analysed by several techniques. Samples included carbonates of intermediate type between primary limestones and secondary dolomites that exhibited transitional porous textures. Powder X-ray diffraction (XRD) used a Rigaku MiniFlex II diffractometer, $\mathrm{CuK}_{\alpha}$ radiation, output voltage of $30 \mathrm{kV}, 15 \mathrm{~mA}$ current, a graphite crystal monochromator, and a detector with a $\mathrm{NaI}(\mathrm{T} 1)$ scintillator and a Be window. Samples were scanned in continuous mode from 3 to $90^{\circ}$ in $0.02^{\circ}$ steps at a rate of $0.40 \% \mathrm{~min}$. Point analyses of minerals were undertaken in a JEOL JXA-8200 Electron Microprobe equipped with 4 WDS spectrometers, operating with a voltage of 15 $\mathrm{kV}$ and a current of $2.5 \times 10-8 \mathrm{~A}$. Qualitative analyses and backscattered electron imaging was done in a HITACHI $3700 \mathrm{~N}$ Environmental SEM working at a voltage of $20 \mathrm{kV}$, a current of 62 to $66 \mu \mathrm{A}$, and $40 \mathrm{~Pa}$ low-vacuum conditions, coupled with a BRUKER Xflash 5010SDD Energy Dispersive X-ray Spectrometer (SEM-EDS). Rock chips were analysed in spots and profiles using a CETAC LSX-213 G2+ laser ablation system coupled to an Agilent 8800 Triple Quad ICP-MS with a frequency of $20 \mathrm{~Hz}$ and laser output energy of $100 \%$ within each spot with a $50 \mu \mathrm{m}$ diameter size. A powdered carbonate standard (NIST 610) was used for internal calibration and prepared in the same way as the samples, and Electron Microprobe $\mathrm{Ca}$ concentrations in the same spots were used as internal standards for quantification purposes. Elements analysed include: $\mathrm{Ca}, \mathrm{Mg}, \mathrm{Al}, \mathrm{Si}, \mathrm{Fe}, \mathrm{Mn}, \mathrm{Sr}, \mathrm{P}, \mathrm{Zn}$, $\mathrm{Cu}, \mathrm{Pb}, \mathrm{Co}, \mathrm{Cd}, \mathrm{Cr}, \mathrm{Ni}, \mathrm{La}, \mathrm{Ce}, \mathrm{Yb}, \mathrm{Eu}, \mathrm{Nd}, \mathrm{Sm}, \mathrm{Dy}, \mathrm{U}$, and Th.

\section{Results and Discussion}

It was observed that extensive calcite replacement is common in many of the sampled dolomite rocks, but XRD did not indicate the presence of high-Mg calcites. Dolomite samples tend to show recrystallized coarse euhedral crystals, whose interstitial space is filled with calcite of later deposition (Fig. 1). The degree of recrystallization is heterogeneous and, in some domains, it is possible to unravel a more complex sequence of events. The core of dolomite crystals in such domains show numerous calcite relicts less than $10 \mu \mathrm{m}$ in size, and a rim of "clean" dolomite with euhedral faces resulting from recrystallization (Fig. 1). Additionally, late calcite precipitation occurs between dolomite crystals, but also inside cleavage planes, which suggests a coupled dissolution/precipitation mechanisms that induced such replacement. These domains are also outlined by oxide phases, which can be interpreted as resulting from precipitation of impurities in dolomite as it was replaced by calcite (Fig. 1). This can be shown by the different trace element content of the calcite relicts, recrystallized dolomite, and late deposited calcite.

Another important feature occurring in these sedimentary units is the extensive dedolomitization process that affected some parts. Intermediate stages of dedolomitization are observed at some locations (PE and CHA), where euhedral crystals of recrystallized dolomite are replaced by calcite (Fig. 1). However, almost total dedolomitization is 
frequent in rocks which preserve their most significant macroscopic textures (development of secondary porosity, saccharoidal texture, high in Fe oxides), but contain microscopic relicts of dolomite $(<5 \mu \mathrm{m})$ in an otherwise coarse-grained calcite matrix. These dedolomitized rocks occur near important fractured domains, some of them showing the development of karstic structures, observed to be filled with Fe-rich materials.
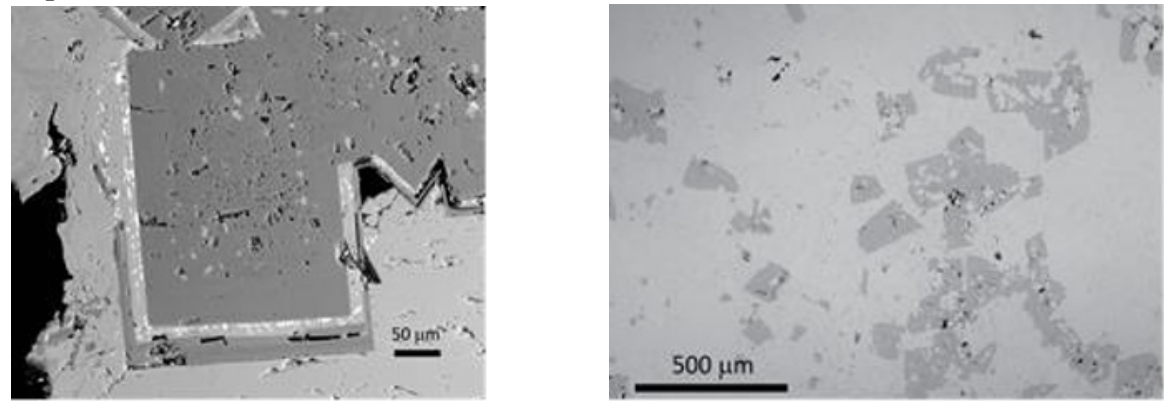

Fig. 1. Backscattered electron (BSE) image of dolomite crystals (dark grey) with a recrystallized rim and a porous core with calcite relicts (left). Late calcite partially replaces for dolomite along cleavage plans, leaving a trail of iron (hydr)oxides - VAL sampled area. BSE image (right) of partially replaced dolomite crystals (dark grey) by calcite (dedolomitization) - CHA sampled area.

Sample petrography allowed calcites to be texturally separated into primary (fully preserving their sedimentary textures), recrystallized, late-deposited (coarse-grained matrix calcites), and in veins. These different calcites show a coherent and overlapping range of concentrations for some trace metal concentrations. However, late-deposited and vein calcites show consistent enrichments of $\Sigma$ REE (between 10 and 30 ppm; remaining calcites mostly $<5$ ppm; Fig. 2), U and Th, and Ba for some late-deposited calcites (Fig. 3).

Dolomite composition form a continuum of concentration in several trace elements coherent with the different calcite generations, usually displaying the extreme high concentrations for some of these elements. Dolomites display higher concentrations in Fe, $\mathrm{Mn}, \mathrm{Sr}, \mathrm{Cu}$, and $\mathrm{Co}$ relative to calcites. Microprobe point analyses in samples from the VAL area as in Fig. 1 (left), using average values with typically 5-7 point analyses, show that calcite relicts are high in $\mathrm{Ce}_{2} \mathrm{O}_{3}(3260 \mathrm{ppm}), \mathrm{ZnO}(1240 \mathrm{ppm})$, and $\mathrm{ThO}_{2}(1040 \mathrm{ppm})$. The primary dolomite replacement is, relative to the calcite relicts, depleted in $\mathrm{Zn}(<290$ ppm), maintains $\mathrm{FeO}(0.08 \%)$ and $\mathrm{MnO}(314 \mathrm{ppm})$ contents, and show no traces of both $\mathrm{Ce}$ and $\mathrm{Th}$. The recrystallized dolomite increases in $\mathrm{FeO}(0.6 \%)$ and has measurable $\mathrm{ZnO}$ contents (408 ppm). Late calcite is "relatively" pure with only higher $\mathrm{MgO}(1.66 \%)$ relative to calcite relicts $(0.35 \%)$ and reported $\mathrm{MnO}$ and $\mathrm{ZnO}$ contents below their respective detection limits (630 and $990 \mathrm{ppm}$, respectively). These late calcite compositions suggest that iron hydroxides inside dolomite cleavage plans likely accumulate at least part of trace metals from dolomite during its partial replacement. These iron hydroxides have $545 \mathrm{ppm}$ of $\mathrm{PbO}, 460$ ppm of $\mathrm{As}_{2} \mathrm{O}_{3}, 2035 \mathrm{ppm}$ of $\mathrm{ZnO}, 385 \mathrm{ppm}$ of $\mathrm{TiO}, 310 \mathrm{ppm}$ of $\mathrm{NiO}$, and 430 ppm of CoO.

The notorious higher contents in Th verified in primary calcites (100 to $500 \mathrm{ppb}$, as opposed to $50 \mathrm{ppb}$ for most other carbonates) is compatible with the reported calcite relicts composition inside dolomite crystals as representing these primary sedimentary calcites. Unlike in late deposited calcites, this Th enrichment is not accompanied with U enrichment as well. 


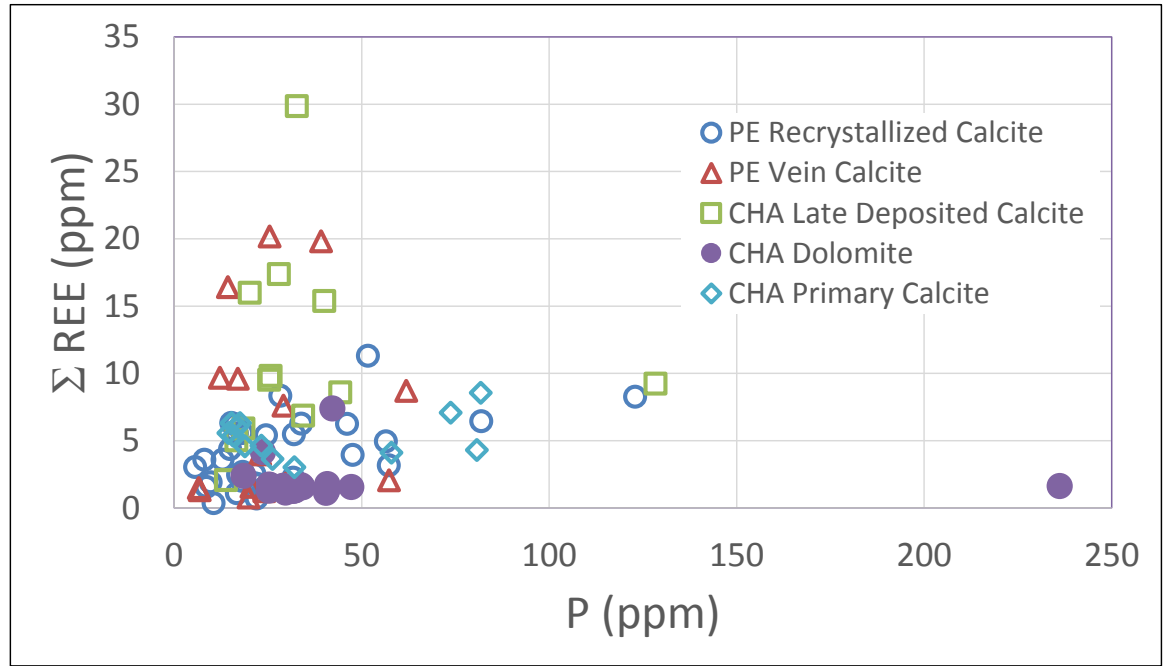

Fig. 2. $\mathrm{P} v s$ sum of REEs (La, Ce, Sm, Dy, Nd, $\mathrm{Yb}$, and $\mathrm{Eu}$ ) in ppm for the different types of analysed carbonates by LA-ICP-MS. PE and CHA refers to two distinct sampling areas.

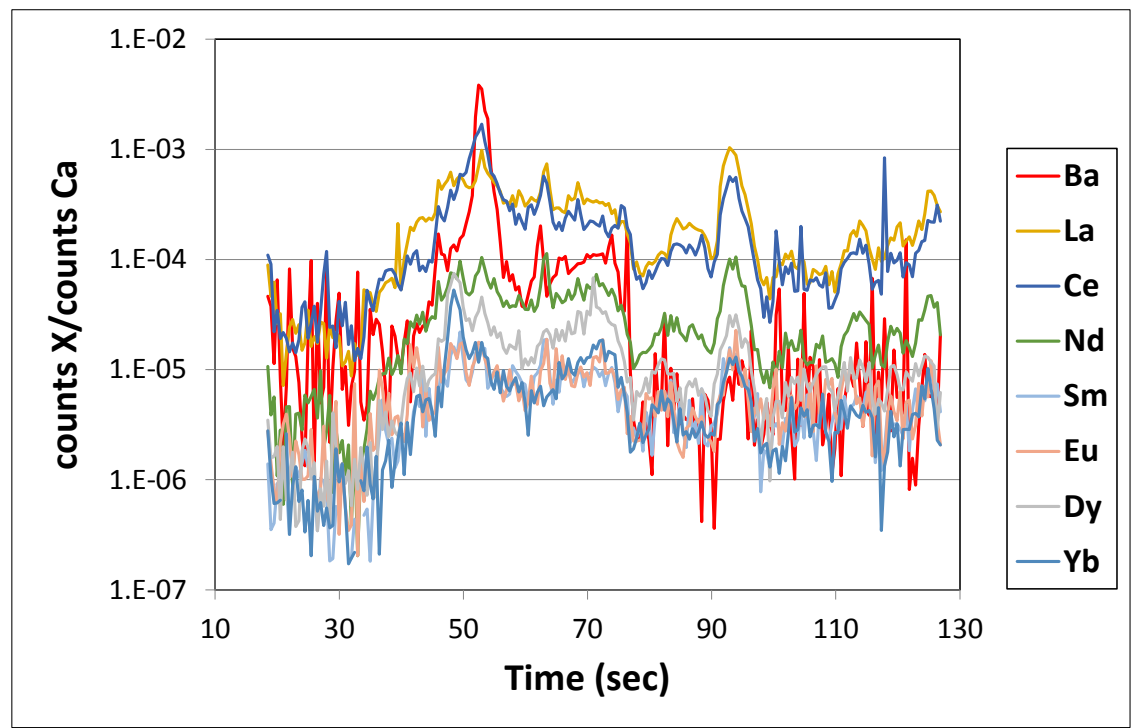

Fig. 3. LA-ICP-MS element profiles across a vein of late calcite (counts normalized to Ca counts to be properly compared) for Ba and selected REE in CHA-3 sample. Scanning speed of profile was 20 $\mu \mathrm{m} / \mathrm{s}$ with a $50 \mu \mathrm{m}$ laser beam diameter. The spike in $\mathrm{Ba}$ (also in $\mathrm{La}$ and $\mathrm{Ce}$ ) likely represent a different mineral phase having $\mathrm{Mn}, \mathrm{Al}$, and some $\mathrm{Mg}$ (not shown; probably Mn oxide). Overall the vein is marked by the higher than average composition of REE and Ba, between 45 and $80 \mathrm{~s}$ which translates to 900 to $1600 \mu \mathrm{m}(0.7 \mathrm{~mm}$ thickness). The higher spike in $\mathrm{Yb}$ at $50 \mathrm{~s}$ relates to a Fe oxide phase with $\mathrm{Zn}$ (not shown).

These analyses suggest that replacement and recrystallization mechanisms tend to preserve, at least partially, trace element contents of primary calcites, whereas late deposited calcites have clearly distinct geochemical signatures, usually depleted in most trace elements, with the exception of REE and Ba. However, they may also display equivalent concentrations in some of the trace elements, such as in $\mathrm{Cu}$ or $\mathrm{Mn}$, as the remaining calcite generations. 
These fluid-assisted events that overprint the primary sedimentary carbonates of the LB have never been studied or put into the context of the LB geological evolution. Three magmatic episodes were identified in the evolution of the LB [e.g., 3]: two cycles of tholeiitic and transitional (sub-alkaline) affinities at $200 \mathrm{Ma}$ and 130-135 Ma, respectively, and a third, more voluminous, at 70-100 Ma of alkaline affinity, with on-shore expression to the South (50 to $60 \mathrm{~km} \mathrm{~S}$ of the studied area, with occurrences that span to the S coast of Portugal). These episodes are known to be important to the thermal evolution of the LB [4], and this work tries to establish the links these magmatic episodes may have had in the sometimes complex evolution of carbonate mineralogy in these limestones. Of particular relevance is the second magmatic cycle identified.

Processes that lead to dolomite formation are known to occur in the vicinity of major fault zones or to be stratigraphically controlled. Although requiring a more accurate and detailed stratigraphic information, the dolomitization process is likely the result of basinal fluids during the diagenetic process in which the contribution from the lower section (Hettangian - Lower Jurassic) evaporitic strata remains to be investigated. In this work, a preliminary assessment of trace element composition in dolomites and later carbonates provides some clues that may be helpful in constraining the fluid chemistry, and eventually its likely source and rock types with which interacted. Therefore, it is relevant to stress that dolomites appear in the same range of trace elements concentration as do the analysed calcites, but often deviates towards an extreme for the concentration range of enriched elements. Accordingly, the REE late enrichments require that the effect of the second magmatic episode be properly assessed as an important source for some of these elements. However, it is not possible to define which mechanism prevailed for dolomite formation, either as dissolution/precipitation [5] or growth-driven pressure solution [6] of calcite. Dedolomitization processes on the other hand resulted from calcite-saturated fluids promoting the substitution of dolomite by a dissolution/precipitation mechanisms in which $\mathrm{Mg}$ is transported away from these zones. Dedolomitization processes are usually associated with a $\mathrm{Ca}$ - and sulphate-rich fluids with karst generation [7, 8], however in the studied area there is no evident availability of a calcium sulphate source.

Acknowledgements. Funding for this research was received from UID/GEO/50019/2013 - IDL, by FCT; Project ALT20-03-0145-FEDER-000017 of the Portugal2020 program. The comments and criticisms of three anonymous reviewers is greatly appreciated and considerably improved the manuscript.

\section{References}

1. A. Azeredo, Geol Soc London, Spec Pub, 149, 281-314 (1998)

2. J.C. Kulberg, et al., Geologia de Portugal, Escolar Editora, 2, 195-347 (2013)

3. R. Miranda, et al., Cretaceous Res, 30, 575-586 (2009)

4. R. Pereira, T. M. Alves, J. Mata, J Geol Soc, 174, 522-540 (2017)

5. O. Singurindy, B. Berkowitz, J Gephys Res, 39, 1143 (2003)

6. E. Merino, A. Canals, Am J Sci, 311, 573-607 (2011)

7. M.A. Raines, T. A. Dewers, Carbonates and Evaporites, 12, 24-31 (1997)

8. C. Arenas, A. M. Alonso-Zarza, G. Pardo, Sed Geol, 125, 23-45 (1999) 